\title{
Editorial
}

\section{Reimagining Comparative and International Education}

We want to commend Greg William Misiaszek and Lauren Ila Misiaszek, outstanding scholars from Beijing Normal University, for this splendid special issue that resites, reimagines and reinvents comparative and international education. It is an issue of significance because it questions the place, role and conception of 'comparison' as an ontological category; and both the editors and the contributors create a nicely interwoven critical fabric for a post-Covid-19 world. As the editors independently and in tandem demonstrate, comparison is not purely the approach of 'similarities and differences.' Comparison does enrich conceptual change and encourages a kind of world engagement that challenges Western assumptions and worldviews. Indeed, comparative education recognizes the approaches and thinkers of very different cultural traditions where the goal is not necessarily the creation of a synthesis, a meta-language into which all theories can be made commensurate but rather a different view of comparative and international education as a discipline that creates space where new theories can be encouraged and new languages and ways of talking are recognized and respected. The comparative thinker is not simply the standpoint philosopher who inhabits a different cultural tradition but one who develops anew theoretical and grounded perspectives that acknowledges, recognises, and advocates global humanity, its sustainable and peaceful future.

As the editors argue, this issue is essentially an attempt to 'reinvent our comparisons' which is a form of deconstruction of existing categories - 'De-colonializing, De-alienating Comparative Education' - to reassert 'Comparative Education for Peace, Justice, and Planetary Sustainability'. The aim of this deconstruction is to 'critically problematize current comparative and international education (CIE) trends that form these contested terrains and their intersectionalities of 
alignments and conflicts' which involves directing their contributing authors 'to not only describe current CIE trends, but to make explicit which ones need to be disrupted' -- a prescription that focuses on 'Decoloniality, Citizenship and Development, Solidarity and Alienation'. For Lauren Misiaszek, SecretaryGeneral of the World Council of Comparative Education Societies (WCCES) in the period 2016-19, this means 'Stretching and Bending the Field' and being epistemological nimble in recognizing and experiencing the diversity of the world while organizing for a sustainable and just collective future (Santos). It demands a self-reflectivity anchored within their own positionality and experience which in the scholarly context often draws a line between teaching and research and political understandings and commitments.

The group of well renown world scholars that the editors have recruited and assembled here also attests to their standing in the field and the trust others place in them - to explore 'internationalization as a moral project', to theorize global citizenship education in different national contexts, to decolonised the concept of 'context' in CIE and an Oceanian relational ontology, to focus on student mobility and global citizenship after Covid-19, to examine 'how alienation plays out in conditions of advanced neoliberalisation in education' in Brazil and the UK', and African perspectives on 'Decolonizing Knowledge, Education and Social Development' that challenge Eurocentric and monocentric constructions of Africa.

These are weighty themes by expert scholars that are up to the mark for such an issue by distinguished world scholars who together make this an extremely important issue. We wish to thank and congratulate the editors and the contributors to this 'reinvention' of CIE.

Michael A. PETERS and Xudong ZHU 